\title{
Antenatal care among Palestine refugees in Jordan: factors associated with UNRWA attendance
}

Victoria Tittle, ${ }^{1}$ Davara Lee Bennett, ${ }^{1}$ Shakoor Hajat, ${ }^{2}$ Amin Shishtawi, ${ }^{1}$ Wafa'a Zeidan, ${ }^{1}$ Fathia Abuzabaida,,${ }^{1}$ Ghada Ballout, ${ }^{1}$ Ishtaiwi Abu-Zayed, ${ }^{3}$ Majed Hababeh, ${ }^{1}$ Ali Khaderı and Akihiro Seita ${ }^{1}$

${ }^{1}$ Health Department, Headquarters, United Nations Relief and Works Agency for Palestine Refugees in the Near East (UNRWA), Amman, Jordan. ${ }^{2}$ London School of Hygiene and Tropical Medicine, London, United Kingdom. ${ }^{3}$ Health Department, Field Office Jordan, UNRWA, Amman, Jordan. (Correspondence to: Victoria Tittle: vickytittle@gmail.com).

\begin{abstract}
Background: Maternal and neonatal mortality is a global issue acknowledged by the Sustainable Development Goals (SDGs). Adequate ante-natal care (ANC) is pivotal to reducing these mortality rates, while understanding why women don't attend ANC is crucial to addressing the SDGs.

Aims: Using routine primary health care data to determine the factors associated with inadequate attendance by Palestine refugees (PR) to ANC seeking facilities provided by the United Nations Relief and Works agency for Palestine Refugees in the Near East (UNRWA), Jordan.
\end{abstract}

Methods: A backwards logistic regression model incorporating non-health system factors and health system factors, was performed using UNRWA data.

Results: A younger age of women was associated with inadequate ANC visits $(P=0.0009)$ in the non-health systems model. For health system factors, pregnancy risk status, having a gynaecologist review and the health centre attended were factors found to be significantly associated with ANC attendance $(P<0.0001)$.

Conclusions: Understanding the health system factors associated with ANC attendance can lead to changes and improvements in UNRWA's operational policies.

Keywords: antenatal care, maternal health, Palestine, refugees, Jordan

Citation: Tittle V; Bennett DL; Hajat S; Shishtawi A; Zeidan W; Abuzabaida F; et al. Antenatal care among Palestine refugees in Jordan: factors associated with UNRWA attendance. East Mediterr Health J. 2019;25(2):98-103. https://doi.org/10.26719/emhj.18.017

Received: 03/10/15; accepted: 10/07/18

Copyright (C) World Health Organization (WHO) 2019. Some rights reserved. This work is available under the CC BY-NC-SA 3.0 IGO license (https:// creativecommons.org/licenses/by-nc-sa/3.o/igo)

\section{Introduction}

The new Sustainable Development Goals (SDGs) highlight maternal and neonatal health as a global health priority, and aim to reduce the global maternal mortality ratio to less than 70 per 100000 live births, and neonatal mortality rate to less than 12 in 1000 live births by 2030 (1). Simple interventions can help reach these goals. Antenatal care (ANC) is the single most cost-effective intervention for the prevention of neonatal deaths; if $90 \%$ of women receive ANC, $14 \%$ of neonatal deaths could be prevented (2-4). To improve the implementation and viability of ANC globally, WHO devised the "Focused ANC" guidelines, advocating a four-visit ANC model to improve care and pregnancy outcomes (5).

The United Nations Relief and Works Agency for Palestine Refugees in the Near East (UNRWA) delivers primary health care, including maternal and child services, to registered Palestine refugees in Five Fields of operation: Gaza, The West Bank, Syrian Arab Republic, Lebanon and Jordan (6). UNRWA's routine data shows $86 \%$ of women attended four ANC appointments in 2015, falling short of the $90 \%$ target (6). Understanding why women do not attend a minimum of four appointments is a priority for UNRWA. There is little data on the barriers to ANC amongst refugee populations, and no known literature for Palestine refugees. This study aims to address this gap and to investigate the barriers to ANC attendance amongst Palestine refugees in Jordan.

\section{Methods}

Data for this study was taken from the electronic information systems (e-health) of UNRWA's primary health care centres in Jordan. Health information was provided for women who registered a delivery between 1 January and 31 December 2015 at one of three operational e-health centres: Amman New Camp, Irbid New Health Centre and Jerash Camp. These health centres were selected because only these had fully operational e-health at the start of the study period. Jordan field was selected because of its relative economic and political stability.

\section{Exclusion criteria}

Cases of miscarriage and stillbirths prior to full gestation were excluded. UNRWA guidelines advise an increased frequency of ANC visits for moderate and high-risk pregnancies, and WHO focused, four ANC visits for low-risk births. Due to the impact of pregnancy risk status on number of ANC visits, patients with missing data on risk status were excluded from the dataset. 


\section{Variables}

The outcome variable is the number of ANC visits made by wome during their pregnancy in the defined study period. ANC visits for subsequent pregnancies during the defined study period were excluded. This variable was binary, with fewer than four ANC visits during pregnancy $(<4 \mathrm{ANC})$ categorized as 1 , and attendance of four or more ANC appointments (4+ANC) as o.

Twenty explanatory variables were extracted from the e-health system. Variables were divided into health system-related factors and non-health system related factors to distinguish between variables that related to UNRWA's health system. Non-health system variables included: age; education level (illiterate, primary, secondary, diploma, higher education); occupation (unemployed, employed, student, housewife); husband's education level (illiterate, primary, secondary, diploma, higher education); husband's occupation (unemployed, employed, student); living male children (yes = 0 , no = 1); number of miscarriages (grouped into categorises of 0,1 , 2 or more miscarriages); history of stillbirths and/or child death (no $=0$, yes $=1$ ); number of children (grouped into $0-2,3-4,5$ or more children; only seven women had no previous children).

Health system factors included: risk status of pregnancy at first ANC visit and last recorded risk status during pregnancy in order to account for change in risk status; health centre; outcome of pregnancy; proportion of appointments attended, including visits to other UNRWA services; receipt of referrals for services outside of UNRWA (no = o, yes $=1$ ); delivery type; place of delivery; receipt of a gynaecologist review (no $=0$, yes $=1$ ); and receipt of an ultrasound (no $=0$, yes $=1$ ). Risk status of pregnancy was included in this category because it was determined by health centres. Any variable with more than ten percent missing data was excluded from the analysis.

Ethics approval was not required for this study, but the Health Director of UNRWA Headquarters reviewed and approved the proposal.

\section{Statistical analysis}

Descriptive analysis by frequency tables can be seen in Table 1. Crude odds ratios were generated by logistic regression. Associations with $P$-values < 0.1 continued into further analysis. Model 1 included non-health system variables. The second regression model was a combina- tion of health systems and non-health systems factors (Model 2). Both models were backwards models. Data was analysed using StataCorp. 2013 (7).

\section{Results}

A total of 5988 women registered a delivery at Amman New Camp, Irbid New Health Centre and Jerash Camp, in 2015. Four hundred and seventy-five women were excluded because they did not reach full gestation age due to miscarriage or stillbirth, and a further 480 women were excluded because of missing risk status during pregnancy; 5033 women remained in the dataset. One reported case of maternal death remained in the dataset, and five variables were excluded because the level of missing data was high (Table 1).

The median age of women was 26 years old (range 16-47) and the median number of children was 3 (range 0-14). Five ANC visits (range 2-16) was the median number of visits to an UNRWA clinic; $28.67 \%$ ( $n=1443$ ) of patients attended $<4$ ANC.

The univariable analysis yielded nine variables with $P$-values < 0.1: age, number of children, number of miscarriages, living male child, health centre, proportion of appointments attended, receipt of a gynaecologist review, risk status at first visits, and last recorded risk status. Table 2 shows the variables excluded following univariable analysis. Crude ORs found no male children in the family to be associated with < 4ANC (OR 1.17, 95\% CI: 1.01-1.36 $\mathrm{P}=0.04$ ), this was unexpected as having no male children was thought to be associated with attendance. Stratum-specific ORs for the proportion of appointments attended suggest this variable demonstrated an association only because of the last stratum of 'no appointments made' (OR 3.41, 95\% CI: 2.64-4.42, $P=$ $<$ 0.0001). This relationship was expected, but there was little evidence in the other stratum to suggest an association. To ensure the Model 2 was comprehensive, this variable was included.

Model 1 adjusted for each of the following variables in turn: age, number of children, number of miscarriages and living male child (Table 3). Only age was found to be significantly associated with $<4$ ANC $(P=0.0009)$. In Model 2 (Table 4), which includes health system factors, risk status at first visit, receipt of a gynaecologist review, and health centre had significant associations with $<4$ ANC. Moderate and high risk pregnancies at first visit were significantly associated with $<4$ ANC $(P=<0.0001)$

\begin{tabular}{lcc}
\hline Table 1 Excluded variables due to missing data & & Percentage of missing data (\%) \\
\hline Variables & Number of observations $(\boldsymbol{n})$ & 32.94 \\
Occupation & 3375 & 42.78 \\
Education level & 2880 & 52.87 \\
Delivery type & 2372 & 89.99 \\
Delivery complications & 504 & 93.88 \\
Husband's occupation & 308 & 93.96 \\
Husband's education level & 304 & \\
\hline
\end{tabular}




\begin{tabular}{|c|c|c|c|c|c|c|}
\hline Variables & $\begin{array}{l}<4 \text { ANC } \\
\text { visits } n(\%)\end{array}$ & $\begin{array}{c}\text { 4+ ANC } \\
\text { visits } \\
\text { n (\%) }\end{array}$ & Crude OR & $\begin{array}{l}\text { Lower } 95 \% \\
\mathrm{Cl}\end{array}$ & $\begin{array}{c}\text { Upper } 95 \% \\
\text { Cl }\end{array}$ & $\begin{array}{l}P \text {-value } \\
\text { (LRT) }\end{array}$ \\
\hline History of a stillbirth or child death & & & & & & 0.84 \\
\hline No & 1414 (97.99) & 3521 (98.08) & 1 & & & \\
\hline Yes & $29(2.01)$ & 69 (1.92) & 1.05 & 0.68 & 1.62 & \\
\hline $\begin{array}{l}\text { Receipt of an ultrasound scan at } \\
\text { UNRWA }\end{array}$ & & & & & & 0.81 \\
\hline No & $1390(96.33)$ & $3453(96.18)$ & 1 & & & \\
\hline Yes & $53(3.67)$ & $137(3.82)$ & 0.96 & 0.7 & 1.33 & \\
\hline Outcome of pregnancy & & & & & & 0.25 \\
\hline Delivered a child & $1432(99.24)$ & $3576(99.61)$ & 1 & & & \\
\hline Stillbirth & $8(0.55)$ & $11(0.31)$ & 1.82 & 0.73 & 4.52 & \\
\hline Child death & $3(0.21)$ & $3(0.08)$ & 2.5 & 0.5 & 12.39 & \\
\hline $\begin{array}{l}\text { Receipt of referral for other medical } \\
\text { services }\end{array}$ & & & & & & 0.27 \\
\hline No & $1438(99.65)$ & $3569(99.42)$ & 1 & & & \\
\hline Yes & $5(0.35)$ & $21(0.58)$ & 0.59 & 0.22 & 1.57 & \\
\hline Place of delivery & & & & & & 0.72 \\
\hline Hospital & $1435(99.45)$ & $3568(99.39)$ & 1 & & & \\
\hline Private clinic & $8(0.55)$ & $17(0.47)$ & 1.17 & 0.5 & 2.71 & \\
\hline Home & 0 & $5(0.14)$ & - & - & - & \\
\hline
\end{tabular}

after adjusting for health system and non-health system factors (aOR 2.42, 95\% CI: 1.94-3.01 and aOR 7.83, 95\% CI:
5.44-11.26 respectively). However, moderate and high risk pregnancies at last visit were found to have aORs

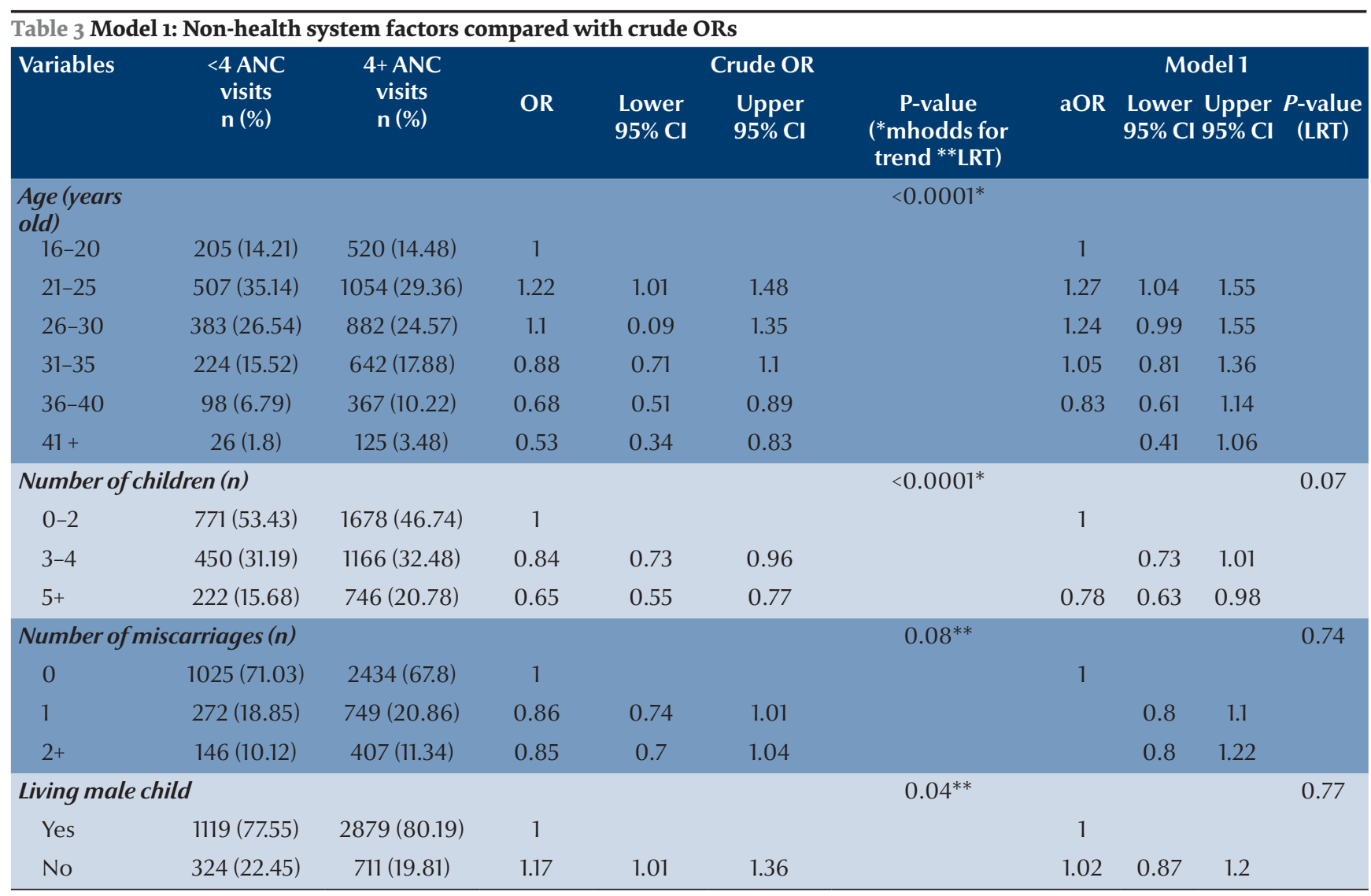




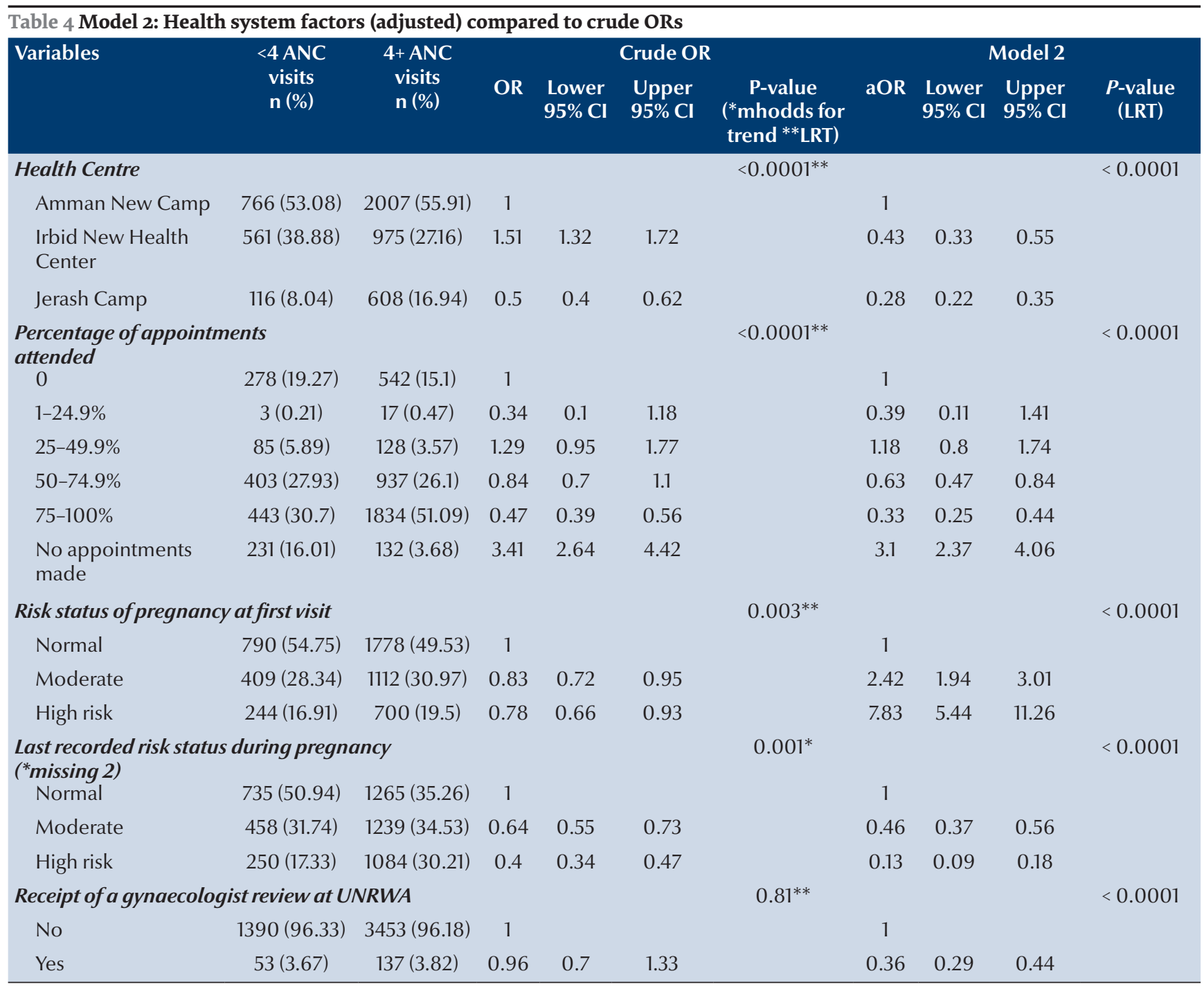

+Adjusted for age, number of children, number of miscarriage, living

of 0.46 (95\% CI: $0.37-0.56)$ and 0.13 (95\% CI: $0.09-0.18$ ), respectively. Receipt of a gynaecologist review was found to be protective against inadequate ANC attendance (aOR 0.36, 95\% CI: 0.29-0.44, P = < 0.0001). Irbid and Jerash health centres in the adjusted model were also found to be protective, compared to Amman New Camp health centre (aOR 0.43, 95\% CI: $0.33-0.55$ and aOR $0.28,95 \% \mathrm{CI}$ : $0.22-0.35, P=<0.0001)$.

\section{Discussion}

Having a moderate and high risk status pregnancy at the first ANC visit is strongly associated with < 4 ANC (aOR 2.42, 95\% CI: $1.94-3.01$ and aOR 7.83, 95\% CI: 5.44-11.26 respectively), but conversely, the aOR for higher risk pregnancies at last ANC visit is 0.46 and 0.13 (95\% CI: $0.37-0.56$ and $0.09-0.18$, respectively, $P=<0.0001$ ). This may be due to higher risk women seeking care outside of UNRWA at the start of the pregnancy, while those with a changing risk status, or with higher risk but unable to attend other facilities, continue with UNRWA care. Information on health-seeking behaviours outside of UNRWA facilities is not available. Gynaecologists review specialist cases at UNRWA's health clinics, including moderate and highrisk pregnancies, and this may be the reason why women who are unable to attend other facilities remain with UNRWA. Specialist services or seeing a gynaecologist is not discussed in the literature, but pregnancy risk status was reviewed by Tran et al. and found to have no association with adequate ANC in urban or rural areas of Vietnam (8). More data on health-seeking practices among women with higher risk pregnancies is needed in this region and context.

The difference between health centres is interesting and explanations may be related to quality of care, availability of other health care providers, access to care and/or socioeconomic differences between communities. A major limitation of this study is not being able to control for socioeconomic factors, due to missing data. Several studies report wealth or education as a significant factor in ANC care (8-14) and more needs to be done to monitor these trends in the region.

Adjusted ORs for age demonstrate wide CIs and should be interpreted with caution. A number of studies show no association between 4ANC and age in adjusted 
models $(8,15)$. Cultural and social differences may account for the differences between these studies, but more data from this region would be helpful in understanding this relationship.

Ultrasound scans were thought by UNRWA staff to constitute an important determinant of ANC attendance because of strong cultural beliefs in the community that ultrasound scans ensure a safe and normal pregnancy, as well as general cultural preferences for a male child. The data suggests no association between $<4$ ANC and having an ultrasound scan $(P=0.81)$ or male children in model 1 and $2(P=0.77$ and $P=0.83$, respectively). No studies to date have ultrasounds, or seeking out ultrasounds, as a factor for ANC attendance, and qualitative studies on this topic in this Region may guide an understanding of impact of these beliefs. Deo et al. found no significant associations between gender of the last child and adequate ANC, reflecting results found in this study (10).

In a study conducted with women in Western Kenya, Van Eijk et al. found that having experienced a stillbirth or child death was not significantly associated with ANC attendance. This supports our finding that a history of stillbirth or child death is not associated with inadequate $\operatorname{ANC}(P=0.84)[15]$.

\section{Limitations}

Jordan field was selected due to the political and economic stability within the country. Consequently, follow-up with ANC should remain unaffected by these factors. However, Jordan is one of five operational fields and is not representative of all Palestinian refugees in the Region. In Jordan, many Palestinian refugees can access health facilities other than UNRWA facilities at a cost, and the proportion of women who seek ANC outside of UNRWA is currently unknown. Data was only available from a small selection of health centres because of limited availability of ehealth records.

Missing data on education and occupation makes it difficult to compare this population with others around the world. Studies in the field refer to wealth and education status as a factor for ANC attendance. A telephone survey was attempted at the end of study using patient telephone numbers, but was halted when large proportions of mobile numbers were no longer use. There was no proxy data to allow for estimations of missing data and therefore this was excluded. We recognise the major limitation this has on the study, but feel the data is still important for information on this vulnerable population and highlights the need for more research in this region. Data only captures information on Palestinian refugees who attend UNRWA services, and this may not reflect the whole population.

These results add to the current literature, which includes little or no information on Palestinian refugees. Comparing this data to other refugee populations and host country populations may be helpful in obtaining a wider set of data and understanding of the issues in this Region.

Funding: None.

Competing interests: None declared.

\section{Soins prénatals chez les réfugiés palestiniens en Jordanie : facteurs associés à la fréquentation des dispensaires de l'UNRWA}

\section{Résumé}

Contexte : La mortalité maternelle et néonatale est un problème mondial reconnu dans les Objectifs de développement durable (ODD). Si des soins prénatals adéquats sont essentiels pour faire baisser ces taux de mortalité, il est primordial, pour atteindre les ODD, de comprendre pour quelles raisons les femmes ne se tournent pas vers les dispensaires de soins prénatals.

Objectifs : Utiliser les données courantes relatives aux soins de santé primaires afin d'identifier les facteurs associés à une fréquentation insuffisante par les réfugiés palestiniens des dispensaires de soins prénatals que l'Office de secours et de travaux des Nations Unies pour les réfugiés de Palestine dans le Proche-Orient (UNRWA) met à disposition en Jordanie.

Méthodes : Un modèle de régression logistique descendante intégrant des facteurs associés aux systèmes de santé et à d'autres systèmes a été réalisé à l'aide de données de l'UNRWA.

Résultats : Dans le modèle reposant sur les autres systèmes que celui de la santé, une association a été établie entre le jeune âge des femmes et une fréquentation insuffisante des dispensaires de soins prénatals $(p=0,0009)$. Pour ce qui est des facteurs associés aux systèmes de santé, le niveau de risque de la grossesse, des examens pratiqués par un gynécologue ainsi que la fréquentation d'un centre de santé se sont révélés des facteurs liés de façon significative à la consultation de dispensaires de soins prénatals $(p<0,0001)$.

Conclusions : Comprendre les facteurs concernant les systèmes de santé associés à la consultation de dispensaires de soins prénatals peut permettre de modifier et d'améliorer les politiques opérationnelles de l'UNRWA. 
الرعاية السابقة للو لادة بين اللاجئات الفلسطينيات في الأردن: العوامل المرتبطة بالحضور إلى وكالة الأمم المتحدة

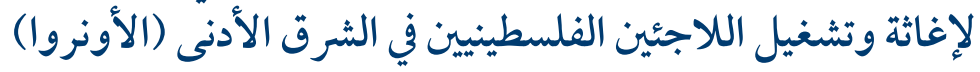

فيكتوريا تتل، دافار الي بينيت، شكور حجات، أمين شيشتاوي، وفاء زيدان، فتحية أبو زبيدة، غادة بلوط، اشتيوي أبو زايد، ماجد حبابة، علي خضر، أكيهيرو سيتا

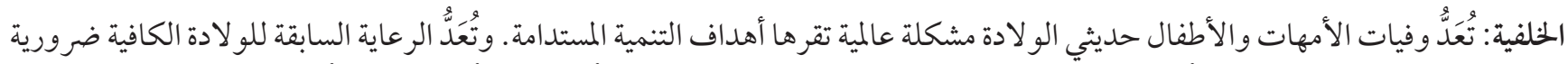

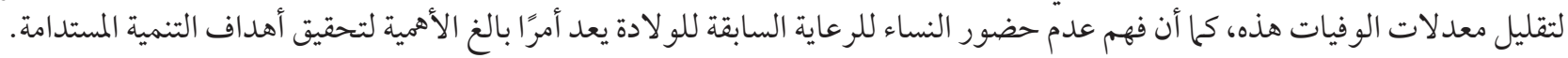
الأهداف: استخدمت بيانات الرعاية الصحية الأولية الروتينية لتحديد العوامل المرتبطة بالحضور غير الكافي للاجئات الفلسطينيات إلى المرافت التي تقدِّم الرعاية السابقة للو لادة والتي توفرها وكالة الأمم المتحدة لإغاثة وتشغيل اللاجئين الفلسطينيين في الشرق الأديني لأدنى (الأونروا)، الأردن.

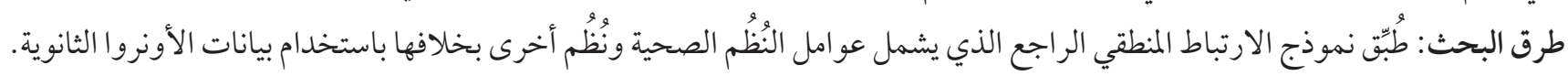

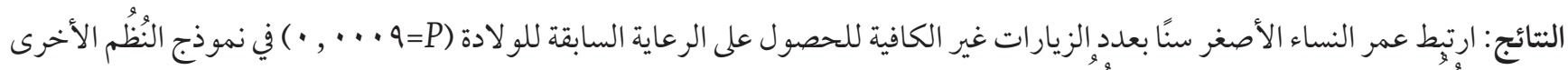

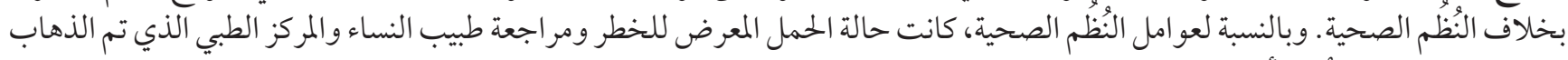

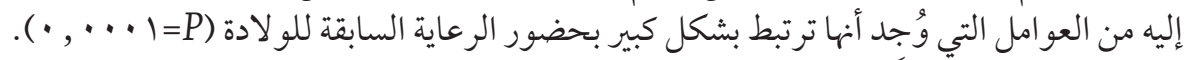

الاستنتاجات: يؤدي فهم عو امل النظام الصحي المرتبطة بحضور الرعاية السابقة للو لادة إلى إدخال تغييرات وتحسينات في السياسات التشغيلية لأؤونروا.

\section{References}

1. UN Sustainable Development Goals. United Nations; 2015 (http://www.un.org/sustainabledevelopment/\#)

2. Villar J, Baaqeel H, Piaggio G, Lumbiganon P, Miguel Belizan J, Farnot U, et al. WHO antenatal care randomized trial for the evaluation of a new model of routine antenatal care. Lancet. 2001;357:1551-64.

3. Carroli G, Villar J, Piaggio G, Khan-Neelofur D, Gülmezoglu M, Mugford M, et al. WHO systematic review of randomised controlled trials of routine antenatal care. Lancet. 2001;357:1565-70.

4. Lincetto O, Mothebesoane-Anoh S, Gomez P, Munjanja S. Antenatal Care. IJSR. 2013;2(2):51-62.

5. Provision of effective antenatal care. World Health Organisation; 2006 (http://www.who.int/reproductivehealth/publications/ maternal_perinatal_health/effective_antenatal_care.pdf)

6. UNRWA. Department of Health's Annual Report. Amman: UNRWA; 2014.

7. STATA Statistical Software: Release 13. College Station, TX: StataCorp LP.

8. Tran TK, Gottvall K, Nguyen HD, Ascher H, Petzold M. Factors associated with antenatal care adequacy in rural and urban contexts-results from two health and demographic surveillance sites in Vietnam. BMC Health Serv Res. 2012;12(1):40.

9. Dahiru T, Oche OM. Determinants of antenatal care, institutional delivery and postnatal care services utilization in Nigeria. Pan Afr Med J. 2015;21:1-17.

10. Deo KK, Paudel YR, Khatri RB, Bhaskar RK, Paudel R, Mehata S, et al. Barriers to Utilization of Antenatal Care Services in Eastern Nepal. Front public Heal. 2015;3:197.

11. Gupta S, Yamada G, Mpembeni R, Frumence G, Callaghan-Koru JA, Stevenson R, et al. Factors associated with four or more antenatal care visits and its decline among pregnant women in Tanzania between 1999 and 2010. PLoS One. 2014;9(7)

12. Joshi C, Torvaldsen S, Hodgson R, Hayen A. Factors associated with the use and quality of antenatal care in Nepal: a population-based study using the demographic and health survey data. BMC Pregnancy Childbirth. 2014;14(1):94.

13. Khanal V, Brites da Cruz JL, Mishra SR, Karkee R, Lee AH. Under-utilization of antenatal care services in Timor-Leste: results from Demographic and Health Survey 2009-2010. BMC Pregnancy Childbirth. 2015;15:211.</jrn>

14. Omer K, Afi N, Baba MD, Adamu M, Malami S, Oyo-Ita A, et al. Seeking evidence to support efforts to increase use of antenatal care: a cross-sectional study in two states of Nigeria. BMC Pregnancy Childbirth. 2014;14(1):380.</jrn>

15. van Eijk AM, Bles HM, Odhiambo F, Ayisi JG, Blokland IE, Rosen DH, et al. Use of antenatal services and delivery care among women in rural western Kenya: a community based survey. Reprod Health. 2006;3:2. 